\section{BULLYING SCIENTIFICALLY LINKED TO MALOCCLUSION}

A new study shows that there is a clear link between being bullied and the presence of 'sticking out teeth' or malocclusion.

A team of hospital-based clinicians who primarily treat children with malocclusion have conducted a UK-based study investigating the relationship between being bullied and the presence of a malocclusion, and its effect on an individual's self-esteem and 'oral health-related quality of life'. Three hundred and thirtysix adolescents aged between 10-14 years of age took part in this study which is being published in Journal of Orthodontics (2011; 38: 247-256) this month.

Key findings of the study show that: nearly 13\% of adolescents aged between 10-14 years examined for orthodontic treatment had been bullied; being bullied is significantly associated with 'sticking out teeth';

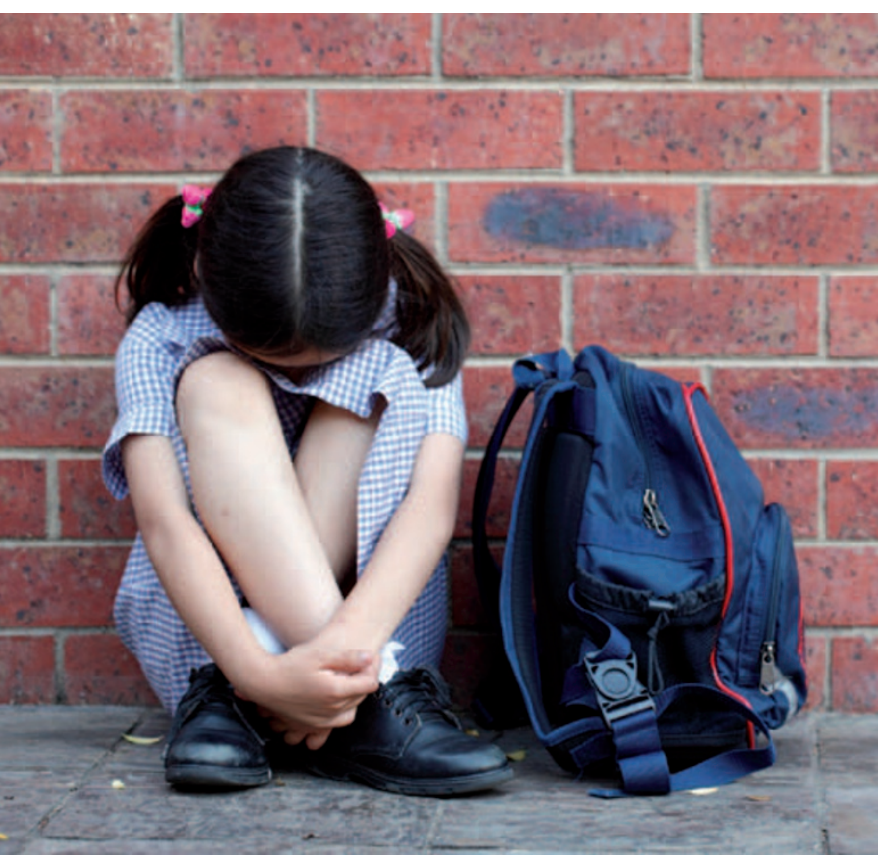

\section{THOUSANDS SPEAK UP ON CPD}

Almost 6,000 General Dental Council (GDC) registrants have responded to a survey carried out as part of the GDC's review of its mandatory continuing professional development (CPD) scheme.

The GDC commissioned ERS: Research to undertake an online survey exploring what registrants think about CPD. The findings will contribute to the wider review that is taking a thorough look at the GDC's current CPD requirements.

The online survey was conducted with a random representative sample of GDC registrants and included questions about their perceptions and motivations for undertaking CPD.

The results are due to be published in early 2012. The GDC introduced compulsory CPD for dentists in these individuals have a higher need for orthodontic treatment based on an aesthetic assessment; and adolescents who are being bullied due to the presence of a malocclusion reported a negative impact on both self-esteem and oral health-related quality of life.

'It has previously been shown that children with "sticking out teeth" and "crooked teeth" are subjected to teasing related to the position and appearance of their teeth,' said Dr Andrew DiBiase, one of the consultants involved in the research. 'However, until this research was carried out the scientific evidence for this was weak and more importantly the psychological effects of this teasing and bullying related to the dental appearance has been unknown'.

The four clinicians have launched a website to disseminate the findings of the study and provide advice for both parents and adolescents who are being bullied due to the presence of a malocclusion. The clinicians are also requesting such people who have been bullied to fill in a web-based questionnaire to enable them to continue to monitor the extent of the problem.

https://sites.google.com/site/ bullyingandorthodontics/

2002 and for dental care professionals (DCPs) in 2008. The current requirements for both registrant categories have been in place since 2008 and the GDC felt the time was right to undertake a review.

Any new CPD requirements will not be introduced before 2013 .

'A modified approach to CPD will be a key step towards developing a workable, proportionate and costeffective approach to revalidation in the future, said Claire Herbert, Head of Revalidation at the GDC.

General comments about CPD can still be sent to CPDReview@ gdc-uk.org.

\section{DIARY}

AOG Conference to Africa

Date: February 2012

www.aoguk.org/events.html

iTOP implant course

Date: 24 March 2012

Location: Scotland

Telephone: 01480862084

Email:info@curaprox.co.uk

www.curaprox.co.uk

ADI Masterclass: Maxillary Alveolar Ridge Regenerative Strategies

Date: 26 March 2012

Venue: Royal College of Surgeons of

England, London

Early-bird fee before 16 December 2011

Telephone: 02084875555

www.adi.org.uk/masterclass 2012

Dental Protection

Dento-Legal Study Day

Date: 30 March 2012

Location: London

Telephone: 02073992914

http://www.dentalprotection.org/uk/ events/dlsd2012

13th Congress of the World

Federation of Laser Dentistry

Date: 26-28 April 2012

Location: Barcelona

Email:wfld2012@kenes.com

www.wfld-barcelona2012.com

British Dental Conference

and Exhibition 2012

Date: 26-28 April 2012

Venue: Manchester Central

Convention Complex

www.bda.org/conference

Excellence in Dentistry 2012

Conference

Date: 26-29 April 2012

Location: Istanbul

www.excellence-in-dentistry.org

The Clinical Innovations

Conference 2012

Date: 18-19 May 2012

Venue: Millennium Gloucester

Hotel \& Conference Centre,

London Kensington

www.clinicalinnovations.co.uk

Dental Sedation Teachers Group

Annual Symposium 2012

Date: 22 May 2012

Venue: St. Paul's Mecure Hotel,

Sheffield

Email: sheelah.harrison@sheffield.ac.uk www.dstg.co.uk 